\title{
REVISTAS ELETRÔNICAS DISPONÍVEIS QUE PODEM CONTRIBUIR PARA A DIVULGAÇÃO DO CONHECIMENTO EM SAÚDE*
}

\author{
Ana Beatriz Carvalho Monteiro** \\ Beatriz Rosana Gonçalves de Oliveira** \\ Cláudia Silveira Vieira** \\ Débora Cristina Ignácio Alves** \\ Lili Marlene Hoffstatter Silva** \\ Luciana Magnani Fernandes** \\ Kátia Cilene Godinho Bertoncello** \\ Maria Célia de Freitas**
}

\section{INTRODUÇÃO}

O processo de comunicação, neste final de século, passou a ser central e prioritário; a tendência delineada para o próximo século indica um crescimento acelerado da informatização, facilidade e rapidez para acessar informações, substituindo a tecnologia e procedimentos até então considerados suficientes.

As informações e a disponibilidade de divulgação das mesmas entre as pessoas do mundo inteiro tornou-se melhor, imediato através do uso de computadores e a criação da internet, possibilitando a aproximação não somente de pessoa a pessoa mas a troca imediata de conhecimentos, culturas além de nos manter informados dos acontecimentos que ocorrem no mundo inteiro através de textos, gravuras ou animações.

Portanto, percebe-se que a internet possibilitará divulgação dessas informações para todas as áreas de estudo incluindo aí a enfermagem, com a utilização de seus recursos tanto para obter dados enriquecendo as experiências e aprendizados como também para fazer conhecido os resultados das pesquisas (CALIRI, 1997). Uma forma de divulgação cada vez mais utilizada é a revista on line.

O trabalho tem como objetivos informar os profissionais da área da saúde sobre as publicações existentes na internet em revistas on line nesta área $\mathrm{e}$ como obtê-las e indicar algumas dessas publicações.

Utilizou como metodologia a consulta bibliográfica de materiais que abordassem o assunto e busca na rede de computação que mostrava as revistas acessíveis pela intenet.

\section{A SAÚDE E AS REVISTAS ON LINE}

Os principais meios de busca e índice existentes para acessar revistas ou publicações on line encontradas na internet, que trazem artigos na área da saúde são apresentados abaixo:

Achei http://www.achei.net

Hotbot http://www.hotbot.com

Altavista http://www.altavista.digital.com

Infoseek http://www.infoseek.com

Bireme http://www.bireme.br

Yahoo http://www.yahoo.com/

Cadê http://www.cade.com.br

lilacs http://www.lilacs.com

Cinahl http://www.cinahl.com

Lycos http://www.lycos.com

Current Contents http://www.isis.com

Medline http://www.medline.com

Dedalus http://www.usp.br/sibi

Nursing Net http://www.nursingnet.com

Fiocruz http://www.fiocruz.br

WebCrawler http://www.metacrawler.com

* Trabalho apresentado à Disciplina de Seminário Avançado de Comunicação do Conhecimento em Enfermagem, responsável: Prof $^{\mathrm{a}} \operatorname{Dr}^{\mathrm{a}}$ Maria Helena Larcher Caliri e $\operatorname{Prof}^{\mathrm{a}} \operatorname{Dr}^{\mathrm{a}}$ Isabel Amélia Costa Mendes

** Alunas do Mestrado em Enfermagem Fundamental da Escola de Enfermagem de Ribeirão Preto da Universidade de São Paulo, por ordem alfabética 
Outra forma de alcançar informações é a interligação através dos links de hipertexto, onde os artigos tem várias palavras e frases "linkadas", ou seja, que remetem diretamente a outros sites na internet, que permitem ao leitor aprofundar seus conhecimentos sobre o assunto tratado, no nível que desejar.

Pesquisadores estão explorando de forma prática essa possibilidade, tais como: Grupos de Publicações Eletrônicas em Medicina e Saúde do Núcleo de Informática Biomédica da Universidade Estadual de Campinas (UNICAMP), cujo endereço do homepage é: http://www.epub.org.br; Grupo de Publicações Eletrônicas em Biologia da Fundação André Tosello (bioline) com homepage: http://www.bdt.org.br/bioline e o Journal of Biological Chemistry, cujo endereço é: http://www.higwire.stanford.edu (SABBATINE, 1998).

O Núcleo de Informática Biomédica da UNICAMP, lançou uma revista on line "Cérebro \& Mente" ou "Brain \& Mind". Divulgando temas de neurociências, saúde mental e psiquiatria, o endereço é: http://www.epub.org.br/cm. Através do projeto Hospital Virtual, disponibilizou na internet a revista "Saúde e Vida On line", cujo endereço eletrônico é: http://www.nib.unicamp.br/svol com artigos sobre: AIDS, diarréias na infância, menopausa, doenças cardíacas, dietas alimentares e câncer.

\section{ONDE PUBLICAR EM REVISTA “ON LINE":}

Ao realizar um estudo e desejando torná-lo público, de acordo com rigor científico, o pesquisador poderá enviar seu artigo para as revistas convencionais que também possuem a forma eletrônica, para análise e posterior publicação de acordo com as exigências das comissões de editoração. Exemplo de algumas revistas: American Journal of Nursing: http:// www.ajn.org.journal/guideline/ajnguide.html

\section{REFERÊNCIAS BIBLIOGRÁFICAS}

01. CALIRI, M.H.L. Usando os recursos da internet na enfermagem. Rev.latino-am.enfermagem. Ribeirão Preto, v.5, n.1, p.97-102, jan.1997.

02. SABBATINI, R.M.E. Revista eletrônica (On line). Available: http://www.nib.unicamp.br/ sabbatin.htm. [10 de junho de 1998].
Journal of Issues in Nursing:

http://www.nursingworld.org/ojin/ojinwrt.htm

New England Journal of Medicine: http:// www.nejn.org/

Bristish Journal of Nursing: http:// www.markalengroup.com/helen.htm

Nursing Journals: http://www.internursing.com/ linkde.htm

Inter Nursing: http://www.internursing.com/ linkde.htm

Journal of Nursing Informatic:

http://www.milkman.cac.psu.edu/oxm/z/OJNI.html

New England Journal of Medicine: http:// www.nejn.org/

Journal of Issues in Nursing: http:// www.nursingworld.org/ajin/

Virtual Nurse: http://virtulnurse.com

Australian Eletronic Journal of Nursing Education: http://www.scu.edu.au/schools/nhcp/aejne/aejnehp.htm Wholenurse: http://www.holenurse.com/

\section{CONSIDERAÇÕES FINAIS}

O processo de publicação, usando a linguagem HTML-hypertext markup language, oferece tantas facilidades que a "auto-publicação", tende a virar uma moda na rede. Este fato ao mesmo tempo desperta preocupações quanto a aspectos da qualidade dos artigos anunciados, se não forem avaliados previamente; como também a possibilidade de surgimento de problemas como: fraude, o plágio e violação dos direitos autorais.

Para a enfermagem, a exemplo de outras áreas da saúde é importante estar investindo nessa tecnologia para divulgação de trabalhos de pesquisas, permitindo ampliação de conhecimentos através dos artigos publicados, inserindo-se nas transformações trazidas pela internet.

03. Saúde na rede (On line). Available: http://www.epub.org.br/correio/cp970321.htm. [18 de junho de 1998].

04. . Revistas On line (On line). Available: http://www.epub.org.br/correio/cp970430.htm.

[18 de junho de 1998]. 